\title{
Usefulness of Cardiac Magnetic Resonance Images for Prediction of Sudden Cardiac Arrest in Patients with Mitral Valve Prolapse: A Multicenter Retrospective Cohort Study
}

Jae-Hyuk Lee

Yonsei University Health System

Jae-Sun Uhm

Yonsei University Health System

Young Joo Suh

Yonsei University Health System

Min Kim

Yonsei University Health System In-Soo Kim

Yonsei University Health System

Moo-Nyun Jin

Yonsei University Health System

Min Soo Cho

Asan Medical Center

Hee Tae Yu

Yonsei University Health System

Tae-Hoon Kim

Yonsei University Health System

Yoo Jin Hong

Yonsei University Health System

Hye-Jeong Lee

Yonsei University Health System

Chi Young Shim

Yonsei University Health System

Young Jin Kim

Yonsei University Health System

Jun Kim

Asan Medical Center

Jong-Youn Kim

Yonsei University Health System 


\section{Boyoung Joung}

Yonsei University Health System

\section{Geu-Ru Hong}

Yonsei University Health System

\section{Hui-Nam Pak}

Yonsei University Health System

\section{Gi-Byoung Nam}

Asan Medical Center

\section{Kee-Joon Choi}

Asan Medical Center

\section{You-Ho Kim}

Asan Medical Center

Moon-Hyoung Lee ( $\sim$ mhlee@yuhs.ac)

Yonsei University Health System https://orcid.org/0000-0002-7268-0741

\section{Research article}

Keywords: Arrhythmia, Gadolinium, Magnetic resonance imaging, Mitral valve prolapse, Sudden cardiac death, Ventricular tachycardia, Ventricular fibrillation

Posted Date: September 15th, 2020

DOl: https://doi.org/10.21203/rs.3.rs-69242/v1

License: (c) (i) This work is licensed under a Creative Commons Attribution 4.0 International License. Read Full License

Version of Record: A version of this preprint was published at BMC Cardiovascular Disorders on November 17th, 2021. See the published version at https://doi.org/10.1186/s12872-021-02362-2. 


\section{Abstract}

Background: An association has been identified between mitral valve prolapse (MVP) and sudden cardiac arrest (SCA), and ventricular arrhythmias (VA). This study aimed to elucidate risk factors for SCA or VA in MVP patients.

Methods: MVP patients who had undergone cardiac magnetic resonance (CMR) were retrospectively included. Patients with other structural heart disease or causes of aborted SCA were excluded. Clinical characteristics (sex, age, body mass index, histories of diabetes, hypertension, coronary artery disease, and dyslipidemia), electrocardiographic (PR interval, QRS duration, corrected QT interval, bundle branch block, and atrial fibrillation), echocardiographic [mitral regurgitation grade, prolapsing mitral leaflet, and right ventricular systolic pressure (RVSP)] and CMR [both ventricular ejection fractions, both ventricular end-diastolic and systolic volume indexes, presence of late gadolinium enhancement (LGE), LGE volume and proportion] parameters were analyzed.

Results: Of the 85 patients [age, 55.0 (41.0-65.0) years; 46 men] included, 7 experienced SCA or VA. Significantly young age and wide QRS complex were observed in the SCA/VA group compared to the noSCA/VA group. The patients in the SCA/VA group had significantly lower RVSP, more presence of LGE, greater LGE volume, and higher LGE proportion than those in the no-SCA/VA group. A high risk for SCA or VA was observed in patients with LGE (odds ratio, 45.525; 95\% confidence interval, 2.558-810.140; $P=$ $.009)$.

Conclusions: Presence of LGE on CMR is a risk factor for SCA or VA in MVP patients. High LGE volume and LGE proportion may provide additional information for prediction of SCA or VA.

\section{Background}

Mitral valve prolapse (MVP), a common valvular heart disease affects $2-3 \%$ of the general population.(1, 2) Although MVP is generally regarded as a benign condition, an association between MVP and sudden cardiac arrest (SCA) has been reported by a number of studies.(3-6) A meta-analysis reported the overall prevalence of SCA in MVP as 217 events per 100,000 person-years, a value noticeably higher than that of the general population with a recently reported 42 to 53 events per 100,000 person-years. $(5,7)$ The pathogenesis of SCA in MVP remains unclear. Previous studies proposed a number of possible mechanisms with myocardial fibrosis in cardiac magnetic resonance (CMR) images, mitral apparatus morphology and electrophysiological characteristics such as ventricular ectopy burden.(6) The growing interest in risk factors or predictors of SCA is attributable to its considerable occurrence in patients with MVP. This study therefore aimed to elucidate the risk factors for SCA or ventricular arrhythmia (VA) in patients with MVP.

\section{Methods}




\section{Study population}

This was a multicenter retrospective cohort study. The study design was approved by the institutional review board (IRB number:4-2019-0747 and 2019-1151) and the study was conducted in accordance with the Declaration of Helsinki. The need for the obtainment of informed consent from the study patients, and the need for review by a critical event committee were waived by the IRB due to the retrospective nature of this study and the absence of patient identification data presented.

In total, 117 patients (aged $\geq 18$ years) who were diagnosed with MVP and underwent CMR from January 2000 to June 2019 in three university hospitals were retrospectively included. The exclusion criteria were as follows: 1) presence of concomitant structural heart disease other than MVP; 2) presence of possible causes of SCA other than MVP; 3) CMR performed after mitral valve surgery.

\section{Electrocardiography (ECG) and echocardiography}

In all patients, 12-lead ECG was performed using standard methods. The ECG of each patient at the time of diagnosing MVP was reviewed, and their ECG parameters [PR interval, QRS duration, QT interval, QT interval corrected using Bazett's formula (QTc), and presence of bundle branch block and atrial fibrillation] were obtained.

Following standard methods, transthoracic echocardiography was performed in all patients. The echocardiography at initial diagnosis of MVP was initially analyzed. The criteria for diagnosis of MVP included an abnormal systolic valve motion of the mitral leaflet into the left atrium ( $\geq 2 \mathrm{~mm}$ beyond the annulus) on transthoracic echocardiography.(8) The grades of mitral regurgitation (MR) were categorized into mild, moderate, and severe based on Doppler echocardiography following the standard criteria of the American Society of Echocardiography.(9) The prolapsing mitral leaflet and presence of ruptured chordae tendinae were observed from multiple views. Right ventricular (RV) systolic pressure (RVSP) was estimated by maximal velocity of tricuspid regurgitation and the conventional simplified Bernoulli's equation.

\section{CMR imaging}

In institution 1, CMR was performed either with a 1.5-T scanner (InteraAchieva; Philips Medical Systems, Best, the Netherlands) or 3.0-T scanner (Magnetom Trio; Siemens Medical Solutions, Erlangen, Germany). In institution 2, it was conducted with a 1.5-T system (Achieva; Philips Healthcare, Best, Netherlands) and a 32-channel cardiac coil. In institution 3, 1.5-T MR systems (Vision 1.5T and Avanto 1.5T; Siemens Medical Systems, Erlangen, Germany) were used for this purpose. The CMR protocol of each institution was previously described in details by studies conducted in each center.(10-13) ECG-gated cine imaging was performed using a balanced steady-state free precession sequence. Late gadolinium enhancement (LGE) imaging was performed 10 minutes following the administration of gadobutrol $(0.2 \mathrm{mmol} / \mathrm{kg}$, 
Gadovist; Bayer Schering Pharma AG, Berlin, Germany) at $2 \mathrm{~mL} / \mathrm{s}$. Data acquisition was synchronized with ECG in the mid-diastolic phase to minimize motion artifacts.

All CMR images were analyzed off-line using a dedicated software program (cvi2, Circle Cardiovascular Imaging, Calgary, Alberta, Canada). Left ventricular (LV) ejection fraction (EF), right ventricular ejection fraction (RVEF), LV and RV end-diastolic (EDV) and systolic (ESV) volume index, LGE volume and proportion were all estimated from the CMR images. From short-axis cine images, the left and right ventricular volumes and EF were measured using a semi-automatic segmentation in the software and all volume measurements were normalized to the body surface area. LGE is translated as a relative excess of gadolinium in the pathological tissue compared to the healthy tissue. First, the presence of LGE was visually determined, followed by an evaluation of the pattern in cases where LGE was discovered. In short-axis LGE images, the endocardial and epicardial borders of the LV were manually drawn and the volume and extent of LGE (\%) was automatically quantified by adopting the 5 -standard deviation (SD) method. LGE volume was calculated by multiplying the LGE area by section thickness which was obtained with hyperenhancing pixels on the CMR images with manual tracing. The LGE proportion was calculated by dividing LGE volume by LV myocardium, with the resulting quotient multiplied by 100 . To reduce effects from imaging artifacts and other confounders, LGE confined to RV insertion site was ignored. $(14,15)$

\section{Grouping of patients and analyses}

The medical records, ECG, echocardiography at the time of diagnosing MVP and CMR images were reviewed. Clinical characteristics [sex, age, body mass index (BMI), medical histories of diabetes, hypertension, coronary artery disease, and dyslipidemia] were acquired from the medical records. The VA included ventricular fibrillation and sustained or non-sustained ventricular tachycardia on a single- or 12lead ECG, Holter monitoring, or treadmill test. The patients were classified based on the presentation of SCA or VA into two categories as follows: SCA/VA group and no-SCA/VA group. The baseline characteristics, ECG (PR interval, QRS duration, QTc, and presence of atrial fibrillation and bundle branch block), echocardiographic (MR grade, prolapsed mitral leaflet, presence of ruptured chordae tendinae, and RVSP), and CMR (LVEF, RVEF, LVEDV index, LVESV index, RVEDV index, RVESV index, presence of LGE, LGE volume and proportion) findings were compared between the groups. Associations of baseline characteristics, ECG, echocardiographic and CMR findings with SCA or VA were analyzed.

\section{Statistical analysis}

Baseline characteristics were analyzed using descriptive statistics. Continuous variables were presented as median with inter-quartile range (IQR) for non-normally distributed variables, whereas categorical variables were presented as frequency and percentages. Continuous and categorical variables were compared using Wilcoxon rank-sum test and Fisher's exact test, respectively. To investigate the risk factors for SCA or VA, univariable and multivariable logistic regression were employed to evaluate 
possible factors and estimate odds ratio (OR), 95\% confidence intervals $(\mathrm{Cl})$, and $P$ values. A $P$ value $<.05$ for a two-sided test was considered statistically significant. Statistical Package for the Social Sciences version 25.0 for Windows (IBM Corporation, Armonk, NY, USA) and R software version 3.6.2 (The R foundation for Statistical Computing, Vienna, Austria) were employed in the analysis of data.

\section{Results}

\section{Study population and ECG}

One hundred seventeen MVP patients [age, 57.5 (42.3-67.0) years; 53 males] who underwent CMR were screened. Thirty-two patients were excluded due to congenital heart disease, ischemic cardiomyopathy and prior mitral valve surgery. Following this, the 85 patients [age, 55.0 (41.0-65.0) years; 46 males] left were finally included; of these, 5 patients experienced SCA and 2 patients have experienced VA on ECG during treadmill test for $7.2(3.9-9.1)$ years.

The baseline characteristics of patients in the SCA/VA and no-SCA/VA groups are presented in Table 1. Patients in the SCA/VA group had significantly younger age and wider QRS complex than those in the noSCA/VA group. Between the groups, no significant differences were observed in sex, BMI and medical histories of diabetes, and hypertension. The ECG findings revealed no significant differences in the PR interval, QTc, the presence of atrial fibrillation, and right bundle brunch block (RBBB) between the groups. 
Table 1

Baseline characteristics of MVP patients between two groups.

\begin{tabular}{|c|c|c|c|}
\hline & $\begin{array}{l}\text { SCA/VA group } \\
(n=7)\end{array}$ & $\begin{array}{l}\text { No-SCA/VA group } \\
(\mathrm{n}=78)\end{array}$ & $P$ \\
\hline Age (years) & $41.0(33.0-49.0)$ & $55.0(42.0-65.0)$ & 0.043 \\
\hline Male sex & $6(85.7)$ & $40(51.3)$ & 0.118 \\
\hline BMI $\left(\mathrm{kg} / \mathrm{m}^{2}\right)$ & $22.6(22.2-28.0)$ & $22.7(20.9-24.9)$ & 0.332 \\
\hline DM & $1(14.3)$ & $6(7.7)$ & 0.465 \\
\hline Hypertension & $1(14.3)$ & $21(26.9)$ & 0.671 \\
\hline CAD & $0(0)$ & $4(5.1)$ & $-{ }^{*}$ \\
\hline Dyslipidemia & $0(0)$ & 8 (10.3) & $-{ }^{*}$ \\
\hline \multicolumn{4}{|l|}{ ECG } \\
\hline PR interval (ms) & $181.0(166.0-198.0)$ & $160.0(144.0-186.0)$ & 0.151 \\
\hline QRS duration (ms) & $114.0(104.0-127.0)$ & $96.0(88.0-104.0)$ & 0.005 \\
\hline QTc (ms) & $437.0(421.5-458.5)$ & $444.0(426.0-462.0)$ & 0.693 \\
\hline $\mathrm{AF}$ & $2(28.6)$ & $23(29.5)$ & $>0.999$ \\
\hline LBBB & $0(0)$ & $1(1.3)$ & $-{ }^{*}$ \\
\hline RBBB & $1(14.3)$ & $5(6.4)$ & 0.413 \\
\hline \multicolumn{4}{|c|}{$\begin{array}{l}\text { Values are presented as number (\%) and median (first and third quartiles) for categorical, and } \\
\text { continuous variables, respectively. }\end{array}$} \\
\hline \multicolumn{4}{|c|}{$\begin{array}{l}\text { AF, atrial fibrillation; BMI, body mass index, calculated as weight in kilograms divided by the square of } \\
\text { height in meters; CAD, coronary artery disease; DM, diabetes mellitus; ECG, electrocardiography; LBBB } \\
\text { left bundle branch block; MVP, mitral valve prolapse; QTC, QT interval corrected by Bazett's formula; } \\
\text { RBBB, right bundle branch block; SCA, sudden cardiac arrest; VA, ventricular arrhythmia. }\end{array}$} \\
\hline
\end{tabular}

\section{Imaging findings}

The echocardiographic and CMR findings of patients in the SCA/VA and no-SCA/VA groups are presented in Table 2. Examples of echocardiographic and CMR images of a MVP patient who experienced SCA are illustrated in Figure 1. A significantly low RVSP was observed in the SCA/VA group compared to the noSCA/VA group, as demonstrated by echocardiographic findings. However, no significant differences were 
observed in the MR grade, involved leaflet, and presence of ruptured chordae tendinae between the groups. As revealed by CMR findings, presence of LGE, and LGE volume and proportion were significantly higher and greater in the SCA/VA group than the no-SCA/VA group. Notably, no significant differences were observed in LVEF, RVEF, LVEDV index, LVESV index, RVEDV index, and RVESV index between the groups. 
Table 2

Imaging findings of MVP patients between two groups.

$\begin{array}{ll}\text { SCA/VA group } & \text { No-SCA/VA group }\end{array}$

Echocardiography

MR grade

\begin{tabular}{|c|c|c|c|}
\hline No & $1(14.3)$ & $3(3.8)$ & 0.296 \\
\hline Mild & $2(28.6)$ & $7(9.0)$ & 0.158 \\
\hline Moderate & $0(0)$ & $15(19.2)$ & 0.334 \\
\hline Severe & $4(57.1)$ & $53(67.9)$ & 0.679 \\
\hline \multicolumn{4}{|l|}{ Involved leaflet } \\
\hline Anterior & $5(71.4)$ & $43(55.1)$ & 0.462 \\
\hline Posterior & $1(14.3)$ & $28(35.9)$ & 0.414 \\
\hline Both & $1(14.3)$ & $7(9.0)$ & 0.513 \\
\hline RVSP (mmHg) & $23.0(21.0-27.0)$ & $35.0(28.0-51.0)$ & 0.002 \\
\hline Ruptured chordae tendinae & $1(14.3)$ & $25(32.1)$ & 0.431 \\
\hline \multicolumn{4}{|l|}{ CMR } \\
\hline LVEF (\%) & $51.0(46.6-69.9)$ & $59.7(51.4-67.9)$ & 0.587 \\
\hline LVEDV index $\left(\mathrm{mL} / \mathrm{m}^{2}\right)$ & $127.0(103.2-148.2)$ & $122.3(98.5-159.5)$ & 0.941 \\
\hline LVESV index $\left(\mathrm{mL} / \mathrm{m}^{2}\right)$ & $63.7(31.1-76.0)$ & $49.0(32.6-72.7)$ & 0.776 \\
\hline RVEF (\%) & $54.1(46.7-60.2)$ & $53.2(41.4-59.2)$ & 0.603 \\
\hline RVEDV index $\left(\mathrm{mL} / \mathrm{m}^{2}\right)$ & $99.4(84.1-134.5)$ & $90.5(69.3-128.7)$ & 0.567 \\
\hline RVESV index $\left(\mathrm{mL} / \mathrm{m}^{2}\right)$ & $47.0(31.0-60.8)$ & $41.3(30.5-73.4)$ & 0.956 \\
\hline Presence of LGE & $4(57.1)$ & $4(5.1)$ & $<0.001$ \\
\hline LGE volume $(\mathrm{g})^{*}$ & $15.1(1.6-44.6)$ & $0.4(0.2-0.6)$ & 0.029 \\
\hline LGE proportion (\%)* & $7.8(1.6-16.8)$ & $0.3(0.2-0.4)$ & 0.028 \\
\hline
\end{tabular}

Values are presented as number (\%) and median (first and third quartiles) for categorical, and continuous variables, respectively.

CMR, cardiac magnetic resonance; LGE, late gadolinium enhancement.; LVEDV, left ventricular end diastolic volume; LVEF, left ventricular ejection fraction; LVESV, left ventricular end systolic volume; MR, mitral regurgitation; MVP, mitral valve prolapse; RVEDV, right ventricular end diastolic volume; 
RVEF, right ventricular ejection fraction; RVESV, right ventricular end systolic volume; RVSP, right ventricular systolic pressure; SCA, sudden cardiac arrest; VA, ventricular arrhythmia.

* LGE volume and proportion were measured in 8 patients with LGE in CMR.

\section{Risk factors for SCA/VA}

In univariable analysis, a significant relationship was observed between SCA or VA and young age, wide QRS complex, low RVSP, presence of LGE, large LGE volume, and high LGE proportion. Multivariable analysis demonstrated a significant association between the presence of LGE and SCA or VA (Table 3). Notably, no significant association was observed between the male sex, age, QRS duration, RVSP, LGE volume and proportion, and SCA or VA. 
Table 3

Clinical and CMR findings of patients in SCA/VA group and in no SCA/VA group with presence of LGE.

\begin{tabular}{|c|c|c|c|c|c|c|}
\hline & $\begin{array}{l}\text { Range } \\
\text { of age }\end{array}$ & Sex & $\begin{array}{l}\text { SCA/VA } \\
\text { type }\end{array}$ & $\begin{array}{l}\text { Event } \\
\text { ECG }\end{array}$ & $\begin{array}{l}\text { LGE } \\
\text { on } \\
\text { CMR }\end{array}$ & LGE location and pattern \\
\hline \multirow[t]{7}{*}{$\begin{array}{l}\text { SCA/VA } \\
\text { group }\end{array}$} & $\begin{array}{l}30 \text { 's- } \\
40 \text { 's }\end{array}$ & Male & $\begin{array}{l}\text { Aborted } \\
\text { sudden } \\
\text { cardiac } \\
\text { death }\end{array}$ & VF & Yes & $\begin{array}{l}\text { Multifocal with patchy pattern } \\
\text {-Mesocardial at anteroseptal segment } \\
\text { of basal to mid LV } \\
\text {-Mesocardial to transmural at anterior, } \\
\text { anterolateral, inferolateral, inferior, and } \\
\text { inferoseptal segment of basal to mid } \\
\text { LV }\end{array}$ \\
\hline & $\begin{array}{l}40 \text { 's- } \\
50 \text { 's }\end{array}$ & Male & $\begin{array}{l}\text { Aborted } \\
\text { sudden } \\
\text { cardiac } \\
\text { death }\end{array}$ & VF & Yes & $\begin{array}{l}\text { Mesocardial at inferoseptal segment } \\
\text { of basal LV }\end{array}$ \\
\hline & $\begin{array}{l}20 \text { 's- } \\
30 \text { 's }\end{array}$ & Male & $\begin{array}{l}\text { Aborted } \\
\text { sudden } \\
\text { cardiac } \\
\text { death }\end{array}$ & VF & Yes & $\begin{array}{l}\text { Multifocal } \\
\text {-Transmural at inferior segment of } \\
\text { basal LV } \\
\text {-Subendocardial at anterolateral and } \\
\text { inferolateral segment of basal LV }\end{array}$ \\
\hline & $\begin{array}{l}40 \text { 's- } \\
50 \text { 's }\end{array}$ & Male & $\begin{array}{l}\text { Aborted } \\
\text { sudden } \\
\text { cardiac } \\
\text { death }\end{array}$ & VF & Yes & $\begin{array}{l}\text { Anterolateral and posteromedial } \\
\text { papillary muscles of LV }\end{array}$ \\
\hline & $\begin{array}{l}10 \text { 's- } \\
20 \text { 's }\end{array}$ & Male & $\begin{array}{l}\text { Aborted } \\
\text { sudden } \\
\text { cardiac } \\
\text { death }\end{array}$ & VF & No & - \\
\hline & $\begin{array}{l}60 \text { 's- } \\
70 \text { 's }\end{array}$ & Female & $\begin{array}{l}\text { VA during } \\
\text { treadmill } \\
\text { test }\end{array}$ & VT & No & - \\
\hline & $\begin{array}{l}50 \text { 's- } \\
60 \text { 's }\end{array}$ & Male & $\begin{array}{l}\text { VA during } \\
\text { treadmill } \\
\text { test }\end{array}$ & NSVT & No & - \\
\hline \multirow{4}{*}{$\begin{array}{l}\text { No } \\
\text { SCA/VA } \\
\text { group }\end{array}$} & $\begin{array}{l}\text { 60's- } \\
70 \text { 's }\end{array}$ & Female & - & - & Yes & Focal anterolateral papillary muscle \\
\hline & $\begin{array}{l}50 \text { 's- } \\
60 \text { 's }\end{array}$ & Male & - & - & Yes & Basal septum of LV with linear pattern \\
\hline & $\begin{array}{l}50 \text { 's- } \\
60 \text { 's }\end{array}$ & Male & - & - & Yes & $\begin{array}{l}\text { Basal septum mid layer of LV with } \\
\text { linear pattern }\end{array}$ \\
\hline & $\begin{array}{l}\text { 60's- } \\
70 \text { 's }\end{array}$ & Male & - & - & Yes & $\begin{array}{l}\text { Multifocal with subendocardial pattern } \\
\text {-Inferior and inferoseptal segment og } \\
\text { mid to apical LV } \\
\text {-Inferolateral segment of mid to basal } \\
\text { LV }\end{array}$ \\
\hline
\end{tabular}


60's- Female - $\quad$ - $\quad$ - $\quad$ Yes $\quad$ Anteroseptal segment of mid to basal

70's LV

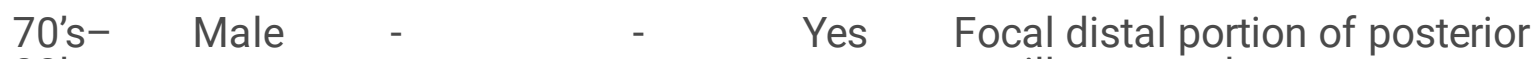
80's papillary muscle

CMR, cardiac magnetic resonance; ECG, electrocardiography; LGE, late gadolinium enhancement; LV, left ventricle; NSVT, non-sustained ventricular tachycardia; SCA, sudden cardiac arrest; VA, ventricular arrhythmia; VF, ventricular fibrillation; VT, ventricular tachycardia. 
Table 4

Risk factors for SCA or VA.

\begin{tabular}{|c|c|c|c|c|}
\hline & Univariable & & Multivariable & \\
\hline & Odds ratio $(95 \% \mathrm{Cl})$ & $P$ & Odds ratio $(95 \% \mathrm{Cl})$ & $P$ \\
\hline Male sex & $5.70(0.66-49.58)$ & 0.115 & $0.47(0.02-11.62)^{*}$ & $0.646^{*}$ \\
\hline Age (year) & $0.95(0.90-0.99)$ & 0.042 & $0.98(0.90-1.06)^{*}$ & $0.556^{*}$ \\
\hline BMI $\left(\mathrm{kg} / \mathrm{m}^{2}\right)$ & $1.13(0.96-1.34)$ & 0.147 & & \\
\hline DM & $2.00(0.21-19.45)$ & 0.550 & & \\
\hline Hypertension & $0.45(0.05-3.98)$ & 0.475 & & \\
\hline \multicolumn{5}{|l|}{ ECG } \\
\hline PR interval (ms) & $1.01(0.99-1.03)$ & 0.359 & & \\
\hline QRS duration (ms) & $1.05(1.01-1.09)$ & 0.017 & $1.07(1.00-1.14)^{\star}$ & $0.069^{*}$ \\
\hline QTc (ms) & $0.99(0.97-1.02)$ & 0.607 & & \\
\hline AF & $0.96(0.17-5.29)$ & 0.959 & & \\
\hline BBB & $2.00(0.21-19.45)$ & 0.550 & & \\
\hline \multicolumn{5}{|l|}{ Echocardiography } \\
\hline \multicolumn{5}{|l|}{ MR grade } \\
\hline Severe & $0.63(0.13-3.03)$ & 0.563 & & \\
\hline \multicolumn{5}{|l|}{ Involving leaflet } \\
\hline Anterior & $3.26(0.36-29.36)$ & 0.293 & & \\
\hline Both & $4.00(0.22-72.18)$ & 0.348 & & \\
\hline $\begin{array}{l}\text { Ruptured chordae } \\
\text { tendinae }\end{array}$ & $0.35(0.04-3.09)$ & 0.347 & & \\
\hline RVSP (mmHg) & $0.83(0.72-0.97)$ & 0.018 & $0.89(0.76-1.04)^{*}$ & $0.135^{\star}$ \\
\hline \multicolumn{5}{|l|}{ CMR } \\
\hline LVEF (\%) & $0.99(0.93-1.06)$ & 0.844 & & \\
\hline LVEDV index $\left(\mathrm{mL} / \mathrm{m}^{2}\right)$ & $1.00(0.98-1.02)$ & 0.878 & & \\
\hline LVESV index $\left(\mathrm{mL} / \mathrm{m}^{2}\right)$ & $1.00(0.98-1.03)$ & 0.927 & & \\
\hline RVEF (\%) & $1.02(0.96-1.09)$ & 0.538 & & \\
\hline
\end{tabular}




\begin{tabular}{|c|c|c|c|c|}
\hline RVEDV index $\left(\mathrm{mL} / \mathrm{m}^{2}\right)$ & $1.00(0.98-1.02)$ & 0.968 & & \\
\hline RVESV index $\left(\mathrm{mL} / \mathrm{m}^{2}\right)$ & $1.00(0.96-1.03)$ & 0.769 & & \\
\hline Presence of LGE & $24.67(4.06-149.77)$ & $<0.001$ & $45.53(2.56-810.14)^{*}$ & $0.009^{*}$ \\
\hline LGE volume (g) & $39.86(1.67-953.09)$ & 0.023 & $\begin{array}{l}159.61(0.23- \\
110593.73)^{\dagger}\end{array}$ & $0.129^{\dagger}$ \\
\hline LGE proportion (\%) & $\begin{array}{l}77.059(1.00- \\
5940.94)\end{array}$ & 0.050 & $0.926(0.81-1.06)^{\ddagger}$ & $0.266^{\ddagger}$ \\
\hline \multirow{2}{*}{\multicolumn{5}{|c|}{$\begin{array}{l}\text { AF, atrial fibrillation; BBB, bundle branch block; BMI, body mass index, calculated as weight in } \\
\text { kilograms divided by the square of height in meters; CAD, coronary artery disease; CMR, cardiac } \\
\text { magnetic resonance; DM, diabetes mellitus; ECG, electrocardiography; LGE, late gadolinium } \\
\text { enhancement; LVEDV, left ventricular end diastolic volume; LVEF, left ventricular ejection fraction; } \\
\text { LVESV, left ventricular end systolic volume; MR, mitral regurgitation; RVEDV, right ventricular end } \\
\text { diastolic volume; RVEF, right ventricular ejection fraction; RVESV, right ventricular end systolic volume; } \\
\text { RVSP, right ventricular systolic pressure; SCA, sudden cardiac arrest; VA, ventricular arrhythmia. } \\
\text { *Odds ratio and } 95 \% \text { confidence interval that were not adjusted by LGE volume and proportion due to } \\
\text { multicollinearity. }\end{array}$}} \\
\hline & & & & \\
\hline \multicolumn{5}{|c|}{$\begin{array}{l}{ }^{\dagger} \text { Odds ratio and } 95 \% \text { confidence interval that were not adjusted by presence of LGE and LGE } \\
\text { proportion due to multicollinearity. }\end{array}$} \\
\hline \multicolumn{5}{|c|}{ 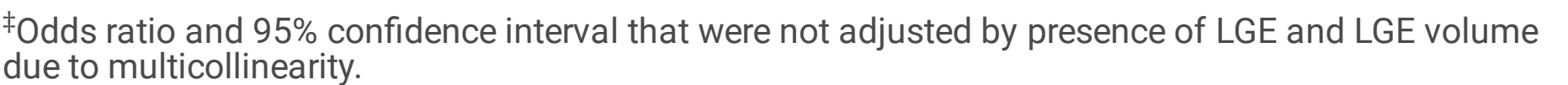 } \\
\hline
\end{tabular}

\section{Discussion}

\section{Main findings}

The following are the main findings of this study: (1) MVP patients who experienced SCA or VA were younger, had wider QRS complex, lower RVSP, more frequent LGE presence, greater LGE volume, and higher LGE proportion than those who did not experience SCA or VA. (2) The presence of LGE was a risk factor for SCA or VA in MVP patients.

\section{Previous studies on risk factors for SCA in patients with MVP}

Young age, female sex, severe valve dysfunction, bileaflet MVP, ventricular ectopy, and LGE in CMR have been suggested as risk factors for SCA in patients with MVP. $(5,6,16)$ However, results are not consistent through the studies. It might be because the inclusion of different study populations and clinical, laboratory, and imaging parameters in the analysis, and the adoption of several definitions of arrhythmic 
events in the studies were various. Thus, there is no consensus on risk stratification for SCA in MVP patients. A number of studies commonly reported young age and female sex as likely risk factors.(3-5, 16) A partial similarity was observed between the present study and past studies with regard to age being a risk factor for SCA though it was not revealed as an independent predictor of SCA. It might be because of the exclusion of old patients who experienced SCA or VA due to other concurrent cardiac diseases or other possible causes of SCA rather than MVP. A possible early detection of MVP in young patients due to SCA occurrence is another likely explanation. Unlike previous studies, no association was demonstrated between sex and SCA or VA in this study.

\section{Significances of LGE on CMR as a risk factor for SCA in patients with MVP}

LGE on CMR may indicate focal myocardial fibrosis, which can be substrate of VA. $(17,18)$ There is an established association between presence of LGE and SCA in patients with ischemic heart disease. However, LGE is an ischemia-related finding in most cases.(18-20) Previous study supported that LGE could be a promising marker of prediction for SCA in patients with MVP.(3) In line with the previous studies, the present study demonstrates the suitability of LGE in the prediction of SCA. Several attempts have been conducted regarding the prediction of SCA or VA with CMR with advancements in CMR technology. In a previous study, the extent of LGE by full width at half maximum method was reported as a strong predictor of recurrent adverse events among SCA survivors.(20) This concept was employed in MVP patients in this study. LGE volume and proportion were larger and higher in the SCA group than the no-SCA group although those were not independent predictors of SCA or VA in patients with MVP. Assessment of the utility of LGE volume and proportion in SCA prediction therefore warrants large-scale studies.

\section{ECG and echocardiographic findings}

Past studies have reported a relationship between T wave inversion in the inferior leads, RBBB, as well as frequent ventricular ectopy, and SCA risk in MVP patients. $(3,21)$ No relationship was demonstrated between bundle branch block and SCA or VA in MVP in the present study. It is well known that an association exists between wide QRS complex and sudden cardiac death in the general population.(22) Although QRS duration as an independent predictor of SCA or VA was not observed in this research, a wider QRS complex was noticed in the SCA/VA group than the no-SCA/VA group. QRS duration as a risk factor of SCA in MVP has not been demonstrated by any study. Further studies are therefore necessary to elucidate the relationship between QRS duration and SCA in MVP patients.

A probable association has been proposed between the severity of MR, myxomatous degeneration of the mitral valve leaflets, involvement of both leaflets, ruptured chordae tendinae, as well as mitral annular disjunction, and SCA in MVP by previous studies. $(4,23-25)$ Notwithstanding, the present study revealed 
no relationship between MR grade, affected leaflets, as well as rupture of chordae tendinae and SCA or VA. The results are indicative of the fact that other noble factors, rather than functional deterioration alone would probably affect the development of SCA or VA. In addition, the present study revealed a low RVSP in the SCA/VA group compared to the no-SCA/VA group. There are no reports on the association between SCA/VA and RVSP in MVP patients yet. The reason for this association remains ambiguous.

\section{Study Limitations}

This was a multicenter retrospective cohort study. The number of patients was small. In addition, a few number of patients had their LGE volume and proportion estimated because of the low incidence of LGE occurrence. In this study, non-sustained ventricular tachycardia (NSVT) was classified alongside SCA. An association between episodes of non-sustained ventricular tachycardia and SCA remains unclear. However, it was reported that patients with MVP and NSVT were more likely to have inducible sustained ventricular tachycardia with programmed stimulation compared with a structurally normal heart.(26) The prevalence of SCA or VA was relatively high (1,143 events per 100,000 person-years) in the present study. It might be because patients who did not undergo CMR were not included and the result could have been influenced by selection bias. Further prospective large-scale studies are therefore necessary.

\section{Conclusions}

The presence of LGE on CMR is a risk factor for SCA or VA in MVP patients. Large LGE volume and high LGE proportion may provide additional information for prediction of SCA or VA.

\section{Abbreviations}

BMI: Body mass index; Cl: Confidence interval; CMR: Cardiac magnetic resonance; ECG:

Electrocardiography; EDV: End-diastolic volume; EF: Ejection fraction; ESV: End-systolic volume; IQR: Interquartile range; IRB: Institutional review board; LGE: Late gadolinium enhancement; LV: Left ventricular; MR: Mitral regurgitation; MVP: Mitral valve prolapse; NSVT: Non-sustained ventricular tachycardia; OR: Odds ratio; RBBB: Right bundle brunch block; RV: Right ventricular; RVEF: Right ventricular ejection fraction; RVSP: Right ventricular systolic pressure; SCA: Sudden cardiac arrest; SD: Standard deviation; VA: Ventricular arrhythmia.

\section{Declarations}

\section{Acknowledgements}

The authors thank Yun-Ho Roh and Won-Jeong Son in the Biostatistics Collaboration Unit, Yonsei University College of Medicine, for their assistance with the statistical analysis.

\section{Authors' contributions}


LJH, UJS, and LMH participated in designing of the work, statistical analysis, and interpretation of data and drafted the manuscript. SYJ, HYJ, LHJ, and KYJ carried out the analysis and interpretation of CMR images. KM, KIS, JMN, YHT, KTH, SJY, KJY, JBY, HGR, PHN, NGB, CKJ, and KYH participated in data collection. CMS, and KJ helped draft and revise of the manuscript. All authors read and approved the final manuscript.

\section{Competing interests}

The authors declare that they have no competing interests.

\section{Funding}

None.

\section{Ethics approval and consent to participate}

This study was approved by the Institutional Review Board of Yonsei University Health system and Asan Medical Center. Informed consent was waived because of the retrospective nature of this study.

\section{Availability of data and materials}

The datasets used and/or analysed during the current study are available from the corresponding author on reasonable request.

\section{Consent for publication}

Not applicable.

\section{References}

1. Freed LA, Levy D, Levine RA, Larson MG, Evans JC, Fuller DL, et al. Prevalence and clinical outcome of mitral-valve prolapse. N Engl J Med. 1999;341(1):1-7.

2. Freed LA, Benjamin EJ, Levy D, Larson MG, Evans JC, Fuller DL, et al. Mitral valve prolapse in the general population: the benign nature of echocardiographic features in the Framingham Heart Study. J Am Coll Cardiol. 2002;40(7):1298-304.

3. Basso C, Perazzolo Marra M, Rizzo S, De Lazzari M, Giorgi B, Cipriani A, et al. Arrhythmic Mitral Valve Prolapse and Sudden Cardiac Death. Circulation. 2015;132(7):556-66. 
4. Narayanan K, Uy-Evanado A, Teodorescu C, Reinier K, Nichols GA, Gunson K, et al. Mitral valve prolapse and sudden cardiac arrest in the community. Heart Rhythm. 2016;13(2):498-503.

5. Han HC, Ha FJ, Teh AW, Calafiore P, Jones EF, Johns J, et al. Mitral Valve Prolapse and Sudden Cardiac Death: A Systematic Review. J Am Heart Assoc. 2018;7(23):e010584.

6. Nalliah CJ, Mahajan R, Elliott AD, Haqqani H, Lau DH, Vohra JK, et al. Mitral valve prolapse and sudden cardiac death: a systematic review and meta-analysis. Heart. 2019;105(2):144-51.

7. Abbadi DR, Purbey R, Poornima IG. Mitral valve repair is an effective treatment for ventricular arrhythmias in mitral valve prolapse syndrome. Int J Cardiol. 2014;177(1):e16-8.

8. Bonow RO, Carabello BA, Chatterjee K, de Leon AC Jr, Faxon DP, Freed MD, et al. 2008 focused update incorporated into the ACC/AHA 2006 guidelines for the management of patients with valvular heart disease: a report of the American College of Cardiology/American Heart Association Task Force on Practice Guidelines (Writing Committee to revise the 1998 guidelines for the management of patients with valvular heart disease). Endorsed by the Society of Cardiovascular Anesthesiologists, Society for Cardiovascular Angiography and Interventions, and Society of Thoracic Surgeons. J Am Coll Cardiol. 2008;52(13):e1-142.

9. Zoghbi WA, Adams D, Bonow RO, Enriquez-Sarano M, Foster E, Grayburn PA, et al. Recommendations for Noninvasive Evaluation of Native Valvular Regurgitation: A Report from the American Society of Echocardiography Developed in Collaboration with the Society for Cardiovascular Magnetic Resonance. J Am Soc Echocardiogr. 2017;30(4):303-71.

10. Youn JC, Hong YJ, Lee HJ, Han K, Shim CY, Hong GR, et al. Contrast-enhanced T1 mapping-based extracellular volume fraction independently predicts clinical outcome in patients with non-ischemic dilated cardiomyopathy: a prospective cohort study. Eur Radiol. 2017;27(9):3924-33.

11. Park CH, Choi EY, Greiser A, Paek MY, Hwang SH, Kim TH. Diagnosis of acute global myocarditis using cardiac MRI with quantitative t1 and t2 mapping: case report and literature review. Korean $\mathrm{J}$ Radiol. 2013;14(5):727-32.

12. Shin DG, Lee HJ, Park J, Uhm JS, Pak HN, Lee MH, et al. Pattern of late gadolinium enhancement predicts arrhythmic events in patients with non-ischemic cardiomyopathy. Int J Cardiol. 2016;222:915.

13. Goo HW. Semiautomatic Three-Dimensional Threshold-Based Cardiac Computed Tomography Ventricular Volumetry in Repaired Tetralogy of Fallot: Comparison with Cardiac Magnetic Resonance Imaging. Korean J Radiol. 2019;20(1):102-13.

14. Turkbey EB, Nacif MS, Noureldin RA, Sibley CT, Liu S, Lima JA, et al. Differentiation of myocardial scar from potential pitfalls and artefacts in delayed enhancement MRI. $\mathrm{Br} J$ Radiol. 2012;85(1019):e1145-54.

15. Almehmadi F, Joncas SX, Nevis I, Zahrani M, Bokhari M, Stirrat J, et al. Prevalence of myocardial fibrosis patterns in patients with systolic dysfunction: prognostic significance for the prediction of sudden cardiac arrest or appropriate implantable cardiac defibrillator therapy. Circ Cardiovasc Imaging. 2014;7(4):593-600. 
16. Spartalis M, Tzatzaki E, Spartalis E, Athanasiou A, Moris D, Damaskos C, et al. Mitral valve prolapse: an underestimated cause of sudden cardiac death-a current review of the literature. J Thorac Dis. 2017;9(12):5390-8.

17. Stevenson WG, Khan H, Sager P, Saxon LA, Middlekauff HR, Natterson PD, et al. Identification of reentry circuit sites during catheter mapping and radiofrequency ablation of ventricular tachycardia late after myocardial infarction. Circulation. 1993;88(4 Pt 1):1647-70.

18. Nazarian S, Bluemke DA, Lardo AC, Zviman MM, Watkins SP, Dickfeld TL, et al. Magnetic resonance assessment of the substrate for inducible ventricular tachycardia in nonischemic cardiomyopathy. Circulation. 2005;112(18):2821-5.

19. Bogun FM, Desjardins B, Good E, Gupta S, Crawford T, Oral H, et al. Delayed-enhanced magnetic resonance imaging in nonischemic cardiomyopathy: utility for identifying the ventricular arrhythmia substrate. J Am Coll Cardiol. 2009;53(13):1138-45.

20. Neilan TG, Farhad H, Mayrhofer T, Shah RV, Dodson JA, Abbasi SA, et al. Late gadolinium enhancement among survivors of sudden cardiac arrest. JACC Cardiovasc Imaging. 2015;8(4):41423.

21. Syed FF, Ackerman MJ, McLeod CJ, Kapa S, Mulpuru SK, Sriram CS, et al. Sites of Successful Ventricular Fibrillation Ablation in Bileaflet Mitral Valve Prolapse Syndrome. Circ Arrhythm Electrophysiol. 2016;9(5).

22. Kurl S, Makikallio TH, Rautaharju P, Kiviniemi V, Laukkanen JA. Duration of QRS complex in resting electrocardiogram is a predictor of sudden cardiac death in men. Circulation. 2012;125(21):2588-94.

23. Grigioni F, Enriquez-Sarano M, Ling LH, Bailey KR, Seward JB, Tajik AJ, et al. Sudden death in mitral regurgitation due to flail leaflet. J Am Coll Cardiol. 1999;34(7):2078-85.

24. Turker Y, Ozaydin M, Acar G, Ozgul M, Hoscan Y, Varol E, et al. Predictors of ventricular arrhythmias in patients with mitral valve prolapse. Int J Cardiovasc Imaging. 2010;26(2):139-45.

25. Miller MA, Dukkipati SR, Turagam M, Liao SL, Adams DH, Reddy VY. Arrhythmic Mitral Valve Prolapse: JACC Review Topic of the Week. J Am Coll Cardiol. 2018;72(23 Pt A):2904-14.

26. Buxton AE, Waxman HL, Marchlinski FE, Josephson ME. Electrophysiologic studies in nonsustained ventricular tachycardia: relation to underlying heart disease. Am J Cardiol. 1983;52(8):985-91.

\section{Figures}



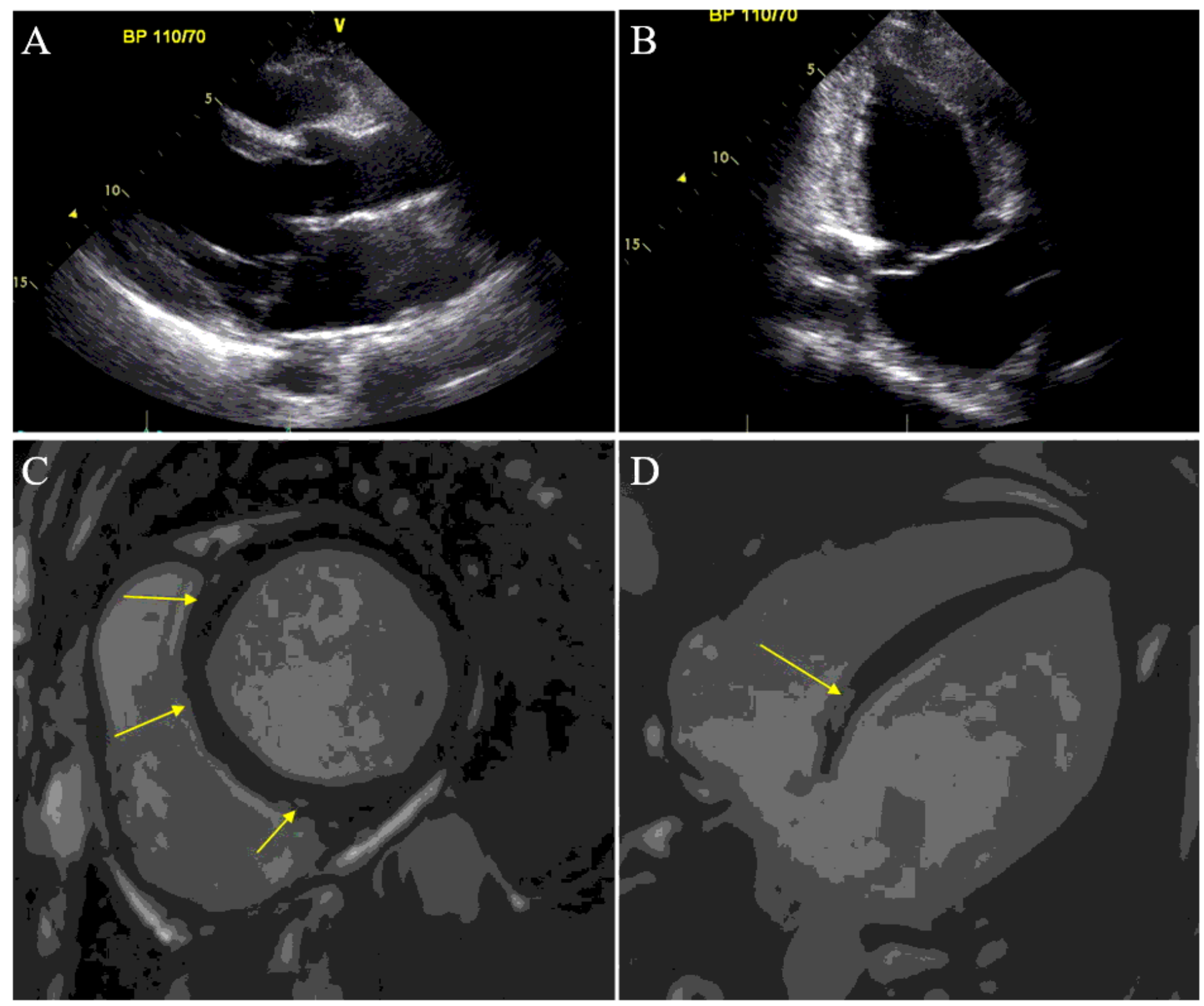

\section{Figure 1}

Echocardiographic and CMR findings of a MVP patient who experienced SCA. Echocardiographic images of parasternal long axis view (A) and apical two chamber view (B) showing prolapse of both mitral leaflets. CMR images of short axis view (C) and four-chamber view (D) showing LGE (arrows) at the mid layer of basal septum. $\mathrm{CMR}=$ cardiac magnetic resonance; $\mathrm{LGE}$ = late gadolinium enhancement; $\mathrm{MVP}=$ mitral valve prolapse; $\mathrm{SCA}=$ sudden cardiac arrest . 